\title{
CARACTERÍSTICAS AGRONÔMICAS E PRODUTIVIDADE DE GENÓTIPOS DE AMENDOIM (Arachis hypogaea L.) EM DIFERENTES POPULAÇÕES
}

\author{
XAVIER, Maxuel Fellipe Nunes ${ }^{1}$ \\ PEROZINI, Alexandre Caetano ${ }^{2}$ \\ ARAÚJO, Charles ${ }^{2}$ \\ GIRON, Felipe Gabriel ${ }^{1}$ \\ SANTIN, Valéria \\ MARTINOTTO, Cristiano ${ }^{2}$ \\ CARMO, Elio Murilo Taborda ${ }^{1}$
}

\begin{abstract}
RESUMO: A população de plantas influencia diretamente na produtividade de uma cultura, por isso, é necessária estabelecer populações de sementes adequadas a cada região de cultivo. Visando avaliar os efeitos de diferentes densidades de sementes em genótipos de amendoim, características agronômicas e produtividade, desenvolveu-se os experimentos na área experimental do Instituto Federal de Educação, Ciências e Tecnologia de Mato Grosso Campus São Vicente, Centro de Referência de Campo Verde, localizada no município de Campo Verde - MT nos anos agrícolas 2017/18 e 2018/19. Os experimentos foram instalados utilizando-se os genótipos de hábito de crescimento rasteiro IAC Caiapó (Experimento 1 e 3) e ereto IAC Tatu-ST (Experimento 2 e 4). O delineamento experimental foi em blocos casualizados, com quatro repetições, e as parcelas foram constituídas de quatro linhas com cinco metros de comprimento e espaçamento de 0,45 metros, totalizando por parcela $9 \mathrm{~m}^{2}$. Os tratamentos foram diferentes densidades de sementes: $10,15,20,25$, e 30 sementes por metro linear (sementes. $\mathrm{m}^{-1}$ ). Diante dos resultados obtidos, pode-se concluir que: Nas condições de campo em que foi desenvolvido esta pesquisa, a produtividade de vagens e grãos no genótipo IAC Caiapó, obteve-se o maior valor médio em 24 sementes. ${ }^{-1}$. Independente da densidade de sementes a produtividade de vagens e grãos é a mesma estatisticamente para o genótipo IAC Tatu-ST.
\end{abstract}

Palavras-chave: Amendoinzeiro. Hábito de crescimento. Densidades. Espaçamento.

\section{AGRONOMIC CHARACTERISTICS AND PRODUCTIVITY OF PEANUT GENOTYPES (Arachis hypogaea L.) IN DIFFERENT POPULATIONS}

\begin{abstract}
SUMMARY: The plant population directly influences the productivity of a crop, so it is necessary to establish seed populations suitable for each crop region. Aiming to evaluate the effects of different seed densities on peanut genotypes, agronomic characteristics and productivity, experiments were developed in the experimental area of the Federal Institute of Education, Science and Technology of Mato Grosso - Campus São Vicente, Campo Verde Reference Center, located in the municipality of Campo Verde - MT in agricultural years 2017/18 and 2018/19. The experiments were installed using the low growth habit genotypes IAC Caiapó (Experiment 1 and 3) and erect IAC Tatu-ST (Experiment 2 and 4). The experimental design was in randomized blocks, with four repetitions, and the plots were composed of four lines with five meters in length and spacing of 0.45 meters, totaling $9 \mathrm{~m}^{2}$ per plot. The treatments were different seed densities: 10, 15, 20, 25, and 30 seeds per linear meter (seeds. $\mathrm{m}^{-1}$ ). Given of the results obtained, it can be concluded that: In the field conditions in which this research was developed, the productivity of pods and grains in the genotype IAC Caiapó, obtained the highest average value in 24 seeds. $\mathrm{m}^{-1}$. Independent of the density, the productivity of pods and grains is the same statistically for the IAC Tatu-ST genotype.
\end{abstract}

Keywords: Peanut butter. Growth habit. Densities. Spacing.

\footnotetext{
${ }^{1}$ Graduando em Agronomia no Instituto Federal de Educação, Ciência e Tecnologia de Mato Grosso/Campus São Vicente, Centro de Referência de Campo Verde, Campo Verde-MT, Brasil. Correspondente: maxuelfellipe90@gmail.com

${ }^{2}$ Professores do IFMT Campus São Vicente. BR 364 Km 329. São Vicente da Serra. CEP: 78.840-000. Fone: (65) 3341-2100. Centro de Referência de Campo Verde, Campo Verde-MT, Brasil
} 


\section{INTRODUÇÃO}

A espécie cultivada Arachis hypogaea L., é originária da América do Sul, e já era cultivada pelas populações indígenas muito antes da chegada dos europeus no final do século 15 . O gênero Arachis compreende cerca de 80 espécies descritas, distribuídas em uma grande variedade de ambientes, desde as regiões costeiras do Brasil e Uruguai até altitudes de $1.450 \mathrm{~m}$ na região dos Andes ao noroeste da Argentina (BERTIOLI et al., 2011).

No Brasil, a safra de amendoim 2018/19 obteve produtividade média de $2.962 \mathrm{~kg} \cdot \mathrm{ha}^{-1}$, com produção total (primeira e segunda safra) de 434,6 mil toneladas (t), sofrendo decréscimo de $16 \%$ em relação a safra 2017/18 (515,9 mil t). Sobre a área plantada, a safra 2018/19 (146,8 mil ha) apresentou incremento de 5\% em relação à safra anterior (139,3 mil ha). O amendoim de primeira safra (verão) representa $97 \%$ (422,2 mil t) do amendoim produzido nacionalmente, ou seja, é a época de cultivo mais importante do país, cultivo comercial (CONAB, 2019).

A população de plantas de uma cultura é definida teoricamente por meio da combinação de diferentes espaçamentos e densidades (COX; REID, 1965). É um dos fatores que se destacam em alterar a produtividade, influenciando diretamente nos componentes de produção (NAKAGAWA et al., 1994). O aumento da população de plantas pode resultar em acréscimo na produção de vagens, todavia, esse aumento pode ser limitado pelas características da cultivar, pelo histórico de fertilidade do solo, ou por condições climáticas da região e risco de ocorrência de doenças (MOZINGO; WRIGHT, 1994; SHOLAR et al., 1995). A alteração na densidade de semeadura é o caminho mais fácil para aumentar a população de plantas, pois o produtor não necessita realizar modificações drásticas na semeadora, embora incremente o gasto de semente por área (SANTOS et al., 2013).

Genótipos de porte ereto frequentemente são cultivados em altas populações, pois utilizam menores área para desenvolvimento dos frutos em relação a materiais do tipo ramados, muito embora possam demostrar resposta na produção de vagens quando a semeadura e adensada (COX; REID, 1965). Recomendam-se para cultivares de porte ereto, o espaçamento de 0,60 m entrelinhas, distribuindo-se 15 a 20 sementes por metro de linha (GODOY et al., 1998).

Plantas de amendoim rasteiro podem apresentar variações no crescimento da parte aérea, principalmente em função de fatores climáticos. Assim, outras configurações de espaçamento e de densidade de semeadura podem ser testadas, dependendo do prévio conhecimento do comportamento dessas cultivares, em cada região, ou época de semeadura, visando obter maior produtividade e/ou melhorar a qualidade do arranquio e enleiramento mecanizado (GODOY et al., 2005). 
Tendo em vista a escassez de informações relacionadas ao comportamento de genótipos de amendoim, principalmente o genótipo de habito de crescimento rasteiro IAC Caiapó e ereto IAC Tatu-ST, cultivadas em diferentes populações, propôs-se no presente trabalho avaliar os efeitos de diferentes densidades de sementes no desenvolvimento e produtividade destes genótipos.

\section{MATERIAL E MÉTODO}

Os experimentos foram desenvolvidos nos anos agrícolas 2017/18 e 2018/19 na primeira quinzena de novembro na área experimental do Instituto Federal de Educação, Ciências e Tecnologia de Mato Grosso - Campus São Vicente, Centro de Referência de Campo Verde localizada no município de Campo Verde - MT, cujas coordenadas geográficas aproximadas são $55^{\circ} 10^{\prime} 08^{\prime \prime} \mathrm{W}$ e $15^{\circ} 32^{\prime} 48^{\prime \prime} \mathrm{S}$, altitude de $736 \mathrm{~m}$. De acordo com a classificação Köppen-Geiger, o clima da região é do tipo Aw (clima tropical com estação seca de inverno).

Durante a realização dos experimentos foram coletados os valores médios diários de temperatura máxima e mínima média do ar $\left({ }^{\circ} \mathrm{C}\right)$, umidade relativa do ar $(\%)$ e precipitação pluvial (mm), nos meses de novembro e dezembro dos anos agrícolas, período entre as instalações dos experimentos e aplicações dos tratamentos, dados registrados no posto meteorológico do INMET expressos na "Figura 1". Os resultados das análises químicas dos solos cujas amostras foram retiradas antes da instalação dos experimentos encontram-se na "Tabela 1". Histórico da área do ano agrícola 2017/18 é de seis anos de experimentação e do ano agrícola 2018/19 é de dois anos de experimentação.

No ano agrícola 2017/18, na primeira quinzena de novembro de 2017, no dia 14-11-2017, realizou-se o preparo do solo de forma convencional, uma aração com arado de disco e duas gradagens leves de destorroamento-nivelamento do solo. Para facilitar o alinhamento a semeadora foi utilizada para fazer os sulcos, para posterior adubação e semeadura que foram feitas nos dias 14-11-2017 (Experimento 1) e 15-11-2017 (Experimento 2). Anterior a semeadura fez-se uma pulverização com auxílio da bomba costal de herbicida glifosato na dose de 1.440 g.i.a.ha ${ }^{-1}$ em pré-plantio. No tratamento das sementes foi utilizado o produto a base de carbendazim + thiron, na dose de $50+50 \mathrm{~g}$ i.a. por $100 \mathrm{~kg}$ de sementes e adubação de semeadura de 200 kg.ha ${ }^{-1}$ de NPK 04-14-08 aplicado ao sulco.

No ano agrícola 2018/19, na primeira quinzena de novembro de 2018, no dia 15-10-2018, realizou-se aplicação de $280 \mathrm{~kg} \cdot \mathrm{ha}^{-1}$ de calcário calcítico e adubação de semeadura de 433,3 kg.ha ${ }^{-1}$ de NPK 00-20-20 aplicado em área total. Com isso realizou-se o preparo do solo de forma convencional, uma aração com arado de disco e duas gradagens leves de destorroamento, nivela- 
mento e incorporação. As semeaduras foram feitas no dia 03-11-2018 (Experimento 3) e 04-112018 (Experimento 4), no tratamento de sementes foi utilizado o produto a base de piraclostrobina + tiofanato metílico + fipronil, na dose de $150 \mathrm{~g}$ i.a. por $100 \mathrm{~kg}$ de sementes.

Figura 1. Valores mensais médios de umidade relativa (\%), temperaturas mínimas, médias, máximas $\left({ }^{\circ} \mathrm{C}\right)$ e precipitação total $(\mathrm{mm})$, nos meses de novembro e dezembro dos anos agrícolas 2017/18 e 2018/19, registrados no posto meteorológico de Campo Verde-MT do Instituto Nacional de Metereologia - INMET.

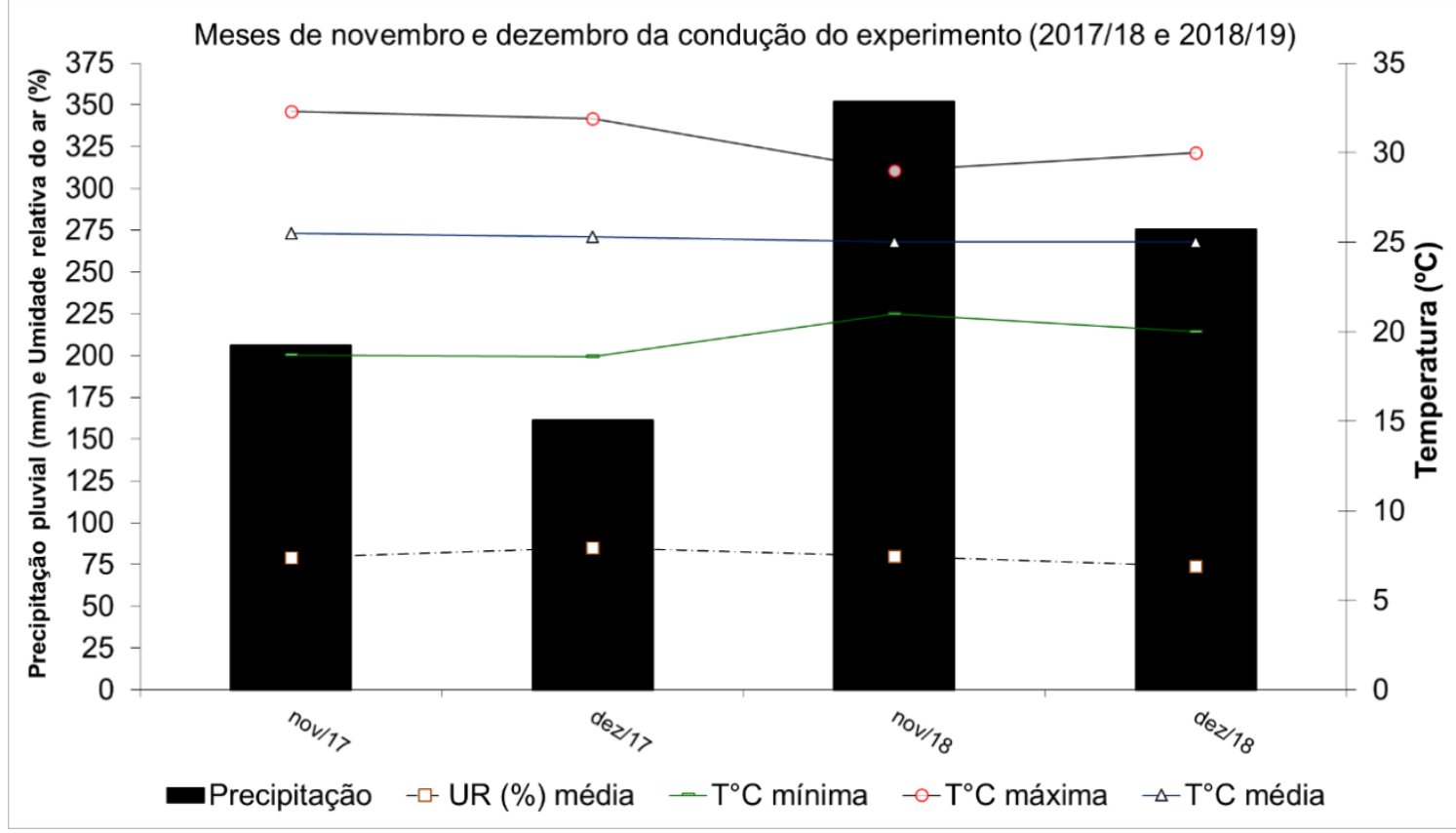

Fonte: Instituto Nacional de Metereologia - INMET, 2019.

Tabela 1. Resultados da análise química dos solos, na profundidade de $0-20 \mathrm{~cm}$, antes da instalação dos experimentos de densidades de sementes. $\mathrm{m}^{-1}$ em Campo Verde-MT.

\begin{tabular}{|c|c|c|c|c|c|c|c|c|c|}
\hline \multirow[t]{2}{*}{ Experimentos } & $\begin{array}{c}\mathrm{pH} \text { em } \\
\mathrm{CaCl}_{2}\end{array}$ & M.O & $\mathbf{P}$ & $\mathbf{K}^{+}$ & $\mathrm{Ca}^{++}$ & $\mathrm{Mg}^{++}$ & $\mathrm{H}^{+} \mathrm{Al}^{3+}$ & $\mathbf{T}$ & $\mathbf{V}$ \\
\hline & & $\mathrm{g} / \mathrm{dm}^{3}$ & \multicolumn{2}{|c|}{$---\mathrm{mg} / \mathrm{dm}^{3}---$} & \multicolumn{4}{|c|}{----------cmol $/ \mathrm{dm}^{3}$---------- } & $\%$ \\
\hline $2017 / 18$ (1 e 2$)$ & 6,4 & 17,1 & 27,4 & 17,8 & 3,55 & 1,45 & 1,16 & 6,2 & 81,4 \\
\hline $2018 / 19$ (3 e 4$)$ & 5,6 & 25,6 & 9,8 & 113,1 & 2,75 & 1,08 & 2,88 & 7,0 & 58,9 \\
\hline
\end{tabular}

Fonte: Elaborado pelos Autores, 2019.

O delineamento experimental utilizado no ano agrícola 2017/18 e 2018/19 foi em blocos casualizados, com quatro repetições, e as parcelas foram constituídas de quatro linhas com cinco metros de comprimento e espaçamento de 0,45 metros entre linhas, totalizando por parcela $9 \mathrm{~m}^{2}$. A área útil considerada nas avaliações foram as duas linhas centrais. Os genótipos utilizados foram o IAC Caiapó (Experimento 1 e 3) e IAC Tatu-ST (Experimento 2 e 4), com densidade de semeadura variável, conforme os tratamentos, considerando um solo de média a alta fertilidade. Os tratamentos avaliados foram cinco densidades de sementes: 10, 15, 20, 25 e 30 sementes por metro linear (sementes. $\left.\mathrm{m}^{-1}\right)$. 
O manejo fitossanitário ao longo do ciclo das plantas de amendoim foi efetuado da seguinte forma: no ano agrícola 2017/18 (Experimento 1 e 2) o controle de plantas daninhas foi realizado com aplicação em área total com o herbicida glifosato na dose de $1440 \mathrm{~g}$ i.a.ha ${ }^{-1}$ em pré-plantio, aplicado no dia 14-11-2017. O manejo de pragas foi realizado com cinco aplicações do inseticida: deltrametrina (0,2 L p.c.ha $\left.{ }^{-1}\right)$ aplicado nos dias 12, 19, 29-12-17, 13-01-18 e 13-0218. O manejo de doenças foi realizado preventivamente com quatro aplicações dos fungicidas: clorotalonil (1,5 L i.a.ha $\left.{ }^{-1}\right)+$ oxicloreto de cobre (2.000 g p.c.ha $\left.{ }^{-1}\right)$ no dia 12-12-17, oxicloreto de cobre $\left(2.000\right.$ g p.c.ha $\left.^{-1}\right)+$ difenoconazol $\left(0,35\right.$ L p.c.ha $\left.^{-1}\right)$ no dia 19-12-17, pyraclostrobina + epoxiconazol $\left(0,6\right.$ L p.c.ha $\left.{ }^{-1}\right)+$ mancozebe $\left(2.000\right.$ g p.c.ha $\left.{ }^{-1}\right)$ no dia 29-12-17 e pyraclostrobina + epoxiconazol (0,6 L p.c.ha $\left.{ }^{-1}\right)+$ mancozebe (2.000 p.c.ha $\left.{ }^{-1}\right)$ no dia 13-01-18.

No ano agrícola 2018/19 (Experimento 3 e 4) o controle de plantas daninhas foi realizado com aplicação do herbicida imazapique na dose de 140 g p.c.ha ${ }^{-1}$ nos dias 21-12-18, 03, 17 e 3101-19. O manejo de pragas foi realizado com sete aplicações de inseticidas: imidacloprido (0,5 L p.c.ha $\left.{ }^{-1}\right)$ nos dias 03-11-18, 21-12-18, 17-01-19, clorfenapir (1,0 L p.c.ha $\left.{ }^{-1}\right)$ nos dias 12-12-18, 03 e 31-01-19, 14-02-19. O manejo de doenças foi realizado preventivamente com sete aplicações de

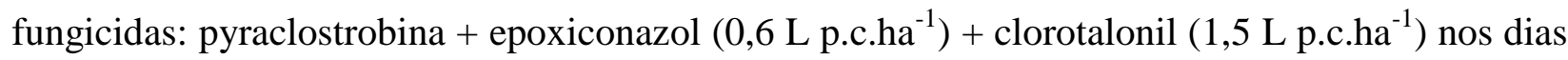
03, 12 e 21-12-18, 03,17, 31-01-19 e 14-02-19.

As avaliações de determinação dos componentes de produção foram feitas no final do ciclo na cultura, quando as vagens atingiram o ponto de maturação fisiológica foi realizado a colheita, no ano agrícola 2017/18 foram nos dias 16-03-18 (IAC Caiapó) e 27-02-18 (IAC TatuST); e no ano agrícola 2018/19 nos dias 08-03-19 (IAC Caiapó) e 18-02-19 (IAC Tatu-ST). Os componentes da produção foram avaliados mediante a colheita e pesagem de amendoim em casca e grãos em dois metros de linha nas duas linhas centrais de cada parcela.

As características avaliadas foram altura de plantas aos 27 (Experimento 1 e 2) e 32 (Experimento 3 e 4) dias após a emergência (DAE), massa seca por planta (g), número de grãos por planta, número de vagens por planta, massa de 100 grãos $(\mathrm{g})$, produtividade de vagens e grãos $\left(\mathrm{kg} \cdot \mathrm{ha}^{-1}\right)$. Das plantas colhidas foram separadas ao acaso, 5 plantas por parcela, para avaliação de massa seca por planta (g), número de grãos e vagens por planta. As medidas de altura de plantas foram efetuadas em nível de campo utilizando uma régua de madeira graduada em centímetros, foram avaliadas três plantas nas duas linhas centrais de cada parcela.

Nos experimentos, os dados foram submetidos à análise de variância (Teste F) e as médias dos tratamentos foram comparadas por regressão linear e quadrática, por meio do programa computacional SISVAR 5.6 (FERREIRA, 2014). 


\section{RESULTADO E DISCUSSÃO}

\section{EXPERIMENTO 1}

Os resultados da análise de variância e os respectivos valores de quadrados médios (tratamento e bloco), médias e coeficiente de variação (C.V.\%) estão apresentados na Tabela 2. Foi observado a diferença significativa a $5 \%$ de probabilidade, pelo teste $\mathrm{F}$, em função da densidade de sementes.m ${ }^{-1}$ com o genótipo IAC Caiapó no ano agrícola 2017/18.

Tabela 2. Quadro da análise de variância de altura de plantas $(\mathrm{cm})$ aos 27 DAE, massa seca por planta (g), número de grãos por planta, número de vagens por planta, massa de 100 grãos (g), produtividade de vagens e grãos $\left(\mathrm{kg} . \mathrm{ha}^{-1}\right)$ em função da densidade de sementes. $\mathrm{m}^{-1}$ do genótipo IAC Caiapó. Campo Verde, 2017/18.

\begin{tabular}{|c|c|c|c|c|}
\hline \multirow{2}{*}{ Variáveis } & \multicolumn{2}{|c|}{ Quadrados Médios } & \multirow{2}{*}{ Média } & \multirow{2}{*}{ C.V.\% } \\
\hline & Tratamento & Bloco & & \\
\hline Altura de plantas aos 27 DAE $(\mathrm{cm})$ & $4,61^{\mathrm{ns}}$ & $1,75^{\mathrm{ns}}$ & 18,65 & 14,82 \\
\hline Massa seca por planta $(\mathrm{g})$ & $53,87^{*}$ & $4,62^{\mathrm{ns}}$ & 9,59 & 27,66 \\
\hline Número de grãos por planta & $287,65^{*}$ & $58,52^{\mathrm{ns}}$ & 23,07 & 25,78 \\
\hline Número de vagens por planta & $112,51^{*}$ & $20,43^{\mathrm{ns}}$ & 13,13 & 29,06 \\
\hline Massa de 100 grãos (g) & $0,18^{\mathrm{ns}}$ & $10,68^{\mathrm{ns}}$ & 63,05 & 4,26 \\
\hline Produtividade de vagens (kg.ha ${ }^{-1}$ ) & $2.456 .972,44^{*}$ & $1.348 .411,60^{\mathrm{ns}}$ & 4.391 & 16,59 \\
\hline Produtividade de grãos $\left(\mathrm{kg} \cdot \mathrm{ha}^{-1}\right)$ & $1.566 .817,71^{*}$ & $854.389,63^{\mathrm{ns}}$ & 3.381 & 16,97 \\
\hline
\end{tabular}

* significativo $5 \%$ de probabilidade; ns - não significativo.

Fonte: Elaborado pelos Autores, 2018.

A Tabela 2 apresenta, a massa seca por planta (g), número de grãos por planta, número de vagens por planta, produtividade de vagens e grãos $\left(\mathrm{kg}_{\mathrm{h}} \mathrm{ha}^{-1}\right)$, em função da densidade de sementes.m ${ }^{-1}$ no genótipo IAC Caiapó, houve diferença significativa. Verifica-se que não houve diferença significativa apenas para altura de plantas $(\mathrm{cm})$ aos 27 DAE e massa de 100 grãos $(\mathrm{g})$.

A altura de plantas $(\mathrm{cm})$ aos 27 DAE em função da densidade de sementes. $\mathrm{m}^{-1}$ utilizados no genótipo IAC Caiapó não diferiram estatisticamente. Nota-se que as diferentes densidades de sementes. $\mathrm{m}^{-1}$ não obtiveram diferença significativa quanto a altura das plantas no início do florescimento, pois Câmara et al. (2016), descreve que nesse período ocorre o início do florescimento, em aproximadamente 4 semanas após a emergência. Estes estudos concordam com Bulgarelli (2008), que também não observou diferença estatística entre as médias de alturas de plantas com o genótipo IAC Caiapó submetido aos tratamentos com 6, 12, 18 e 22 plantas por metro linear $\left(\mathrm{m}^{-1}\right)$ e espaçamento de $0,90 \mathrm{~m}$. Perozini et al. (2014), descrevem que não houve diferença estatística entre as médias de altura de plantas aos 30 DAE, utilizando o genótipo IAC 
Caiapó, cultivado em espaçamento de $0,80 \mathrm{~m}$ e possível densidade de semeadura de 15 sementes. $\mathrm{m}^{-1}$ que resultou no estande de 12 plantas. $\mathrm{m}^{-1}$.

Em relação a massa seca por planta $(\mathrm{g})$, verifica-se que a densidade de sementes. $\mathrm{m}^{-1}$ influenciou-a, com ajuste linear decrescente (Figura 2.A). Observa-se que a maior massa foi obtida no tratamento de 10 sementes. $^{-1}(15,50 \mathrm{~g})$, com decréscimo até o tratamento de 25 sementes. $\mathrm{m}^{-1}(6,13 \mathrm{~g})$. Constata-se que o aumenta a densidade de sementes. $\mathrm{m}^{-1}$ é inversamente proporcional a massa seca das plantas $(\mathrm{g})$, pois as densidade de 25,30 e 20 sementes.m ${ }^{-1}$ possuem as menores massas, ou seja, provavelmente as plantas não ramificaram tanto quanto as submetidas as densidades de 10 e 15 sementes. $\mathrm{m}^{-1}$. Discorda-se de Boiça Junior et al. (2012) que obteve massa seca média por planta de $26,00 \mathrm{~g}$, sendo superior ao dobro da média $(9,59 \mathrm{~g})$ da variável (Tabela 2), utilizando população de 12 a 13 plantas.m ${ }^{-1}$ com genótipo IAC Caiapó.

Figura 2. Massa seca por planta (g) (A), número de grãos por planta (B), número de vagens por planta $(\mathrm{C})$, produtividade de vagens e grãos $\left(\mathrm{kg}^{\left.-h a^{-1}\right)}(\mathrm{D})\right.$, em função da densidade de sementes.m ${ }^{-1}$ do genótipo IAC Caiapó. Campo Verde, 2017/18.
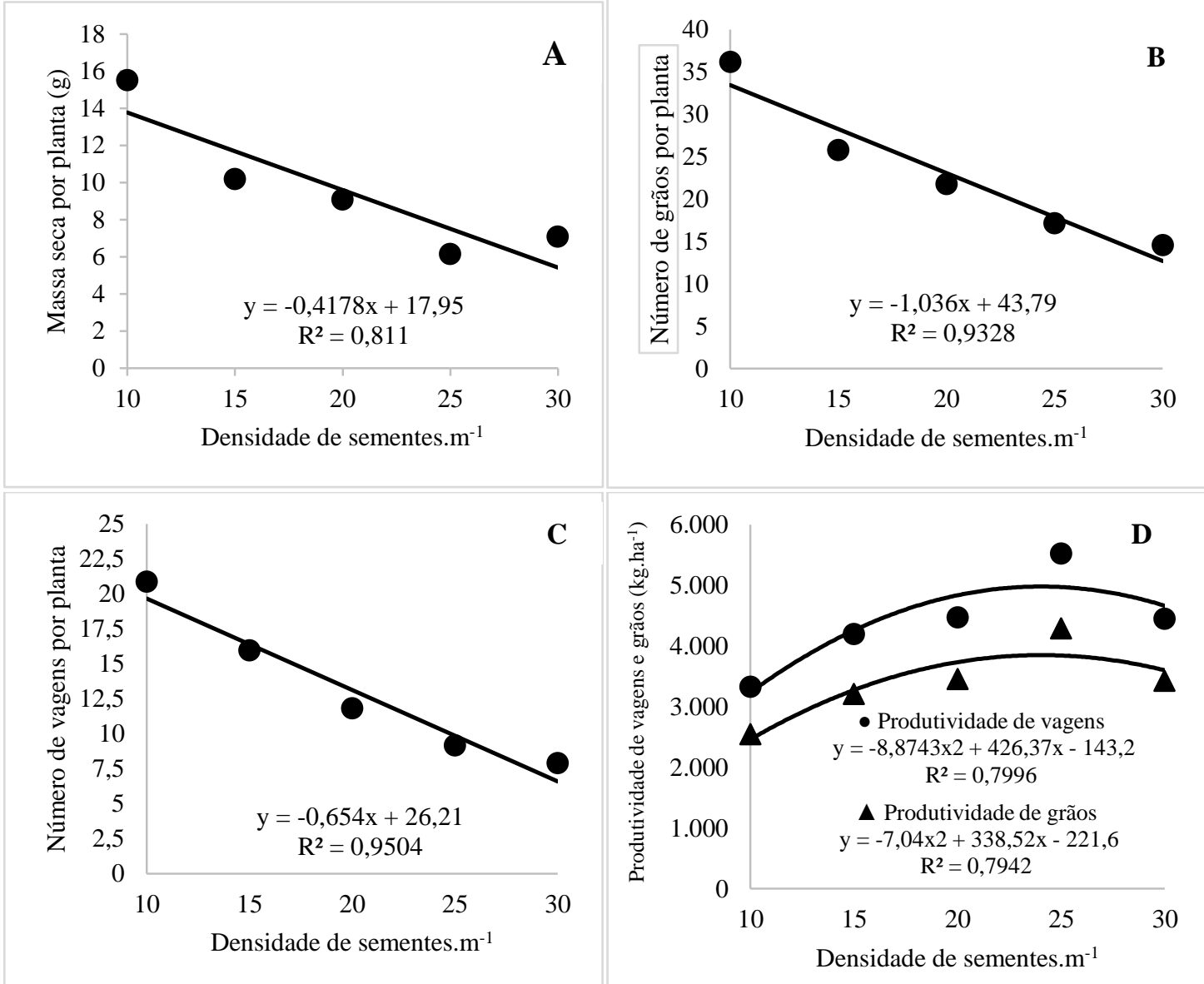

Fonte: Elaborado pelos Autores, 2018.

O número de grãos e vagens por planta obtiveram resultados correlatos, apresentando diferença estatística nas diferentes densidades de sementes. $\mathrm{m}^{-1}$, ambos com ajuste linear decrescente (Figura 2.B e 2.C). Verifica-se que o tratamento de 10 sementes.m $^{-1}$ (36,15 grãos e 
20,85 vagens) apresentou maior média, seguido pelo decréscimo de 60 e $62 \%$ até o tratamento de 30 sementes. $\mathrm{m}^{-1}$ (14,55 grãos e 7,90 vagens), respectivamente. Observa-se que conforme diminui a densidade de sementes, se obtém maior número de grãos e vagens por planta, possivelmente quando as plantas são submetidas a menores densidades se tem menor gasto energético para competir entre as outras, com isso centralizam a energia para a produção de vagens e grãos.

Nesse sentido, concorda-se com os estudos de Barbieri et al. (2016), que utilizando a cultivar rasteira IAC Runner 886 cultivada em espaçamento de $0,45 \mathrm{~m}$ e submetida ao fatorial: três densidades $\left(5,10\right.$ e 15 plantas.m $\left.{ }^{-1}\right)$ e quatro épocas de semeadura $(16 / 02,26 / 02,08 / 03$ e 20/03), observaram em três épocas (26/02,08/03 e 20/03) as maiores quantidades de vagens por planta na menor densidade de plantas (5 plantas. $\left.\mathrm{m}^{-1}\right)$; Bellettini e Endo (2001), utilizando as densidades de $10,15,20$ e 25 sementes. $^{-1}$, descreveram que quanto maior o número de plantas. $\mathrm{m}^{-1}$ menor o número de grãos por planta; Nakagawa et al. (2000), estudando diferentes populações $\left(5,8,11,14,17,20,23\right.$ e 26 plantas.m $\left.^{-1}\right)$, constataram em três safras $(1987 / 88$, 1988/89 e 1989/90) que conforme aumenta as populações diminui-se o número de vagens por planta.

A massa de 100 grãos (g), em função da densidade de sementes. $\mathrm{m}^{-1}$ utilizados no genótipo IAC Caiapó não diferiu significativamente, apresentando massa média de 63,05 g (Tabela 2). Estes resultados concordam com Romanini Junior (2007), que também não encontrou diferença significativa, utilizando o genótipo Runner IAC 886 com massa média de 62,40 g. Entretanto, discordam de Câmara (2016), que descreve massa média de 100 grãos para o genótipo IAC Caiapó de 44,00 à 48,00 g, médias essas aproximadamente 30 à 24\% menores do que a média (Tabela 2).

Em relação as produtividades de vagens e grãos $\left(\mathrm{kg} \cdot \mathrm{ha}^{-1}\right)$, verifica-se a diferença estatística sobre a influência da densidade de sementes, com ajuste quadrático (Figura 2.D). Sobre a produtividade de grãos, com base no ajuste quadrático, 24 sementes. $^{-1}$ é a população ótima com produtividade de grãos máxima de $4.291 \mathrm{~kg} \cdot \mathrm{ha}^{-1}$ para o genótipo IAC Caiapó. Dentre os tratamentos testados, 25 sementes. $\mathrm{m}^{-1}$ apresentou a maior produtividade $\left(4.288 \mathrm{~kg} . \mathrm{ha}^{-1}\right) \mathrm{em}$ relação aos demais tratamentos, diferindo de 10 sementes. $\mathrm{m}^{-1}$ com a menor produtividade $(2.541$ $\left.\mathrm{kg} \cdot \mathrm{ha}^{-1}\right)$.

Portanto, aumentando-se a população de plantas, tem-se aumento na produtividade, mas tais ganhos ocorrem até uma determinada densidade de sementes. $\mathrm{m}^{-1}$, apresentando nos tratamentos de 10 a 25 sementes.m $^{-1}$ um acréscimo de $40 \%$. Estes resultados estão de acordo Fachin et al. (2014), utilizando o genótipo IAC Caiapó, espaçado em 0,70 m e com densidade de 15 plantas. $\mathrm{m}^{-1}$, obtiveram produtividade de grãos $\left(4.040 \mathrm{~kg} \cdot \mathrm{ha}^{-1}\right) 15 \%$ superior a obtida no tratamento de 20 sementes. $\mathrm{m}^{-1}\left(3.449 \mathrm{~kg} \cdot \mathrm{ha}^{-1}\right)$ do presente estudo, que resulta no estande de plan- 
tas mais próximo do comparado. Discordando de Néris (2005), que no estudo na época das águas, apresentou produtividade média de $2.366 \mathrm{~kg} \cdot \mathrm{ha}^{-1}$ com o mesmo genótipo, submetido a 0,70 e 0,90 $\mathrm{m}$ de espaçamento com estande de 18 plantas. $\mathrm{m}^{-1}$.

A produtividade de vagens, apresentou 24 sementes. $\mathrm{m}^{-1}$ com maior produtividade $(4.978$ $\left.\mathrm{kg} \cdot \mathrm{ha}^{-1}\right)$. Estes resultados discordam com Oliveira et al. (2010), que obtiveram produtividade de vagens de $3.475 \mathrm{~kg} . \mathrm{ha}^{-1}$ com o genótipo IAC Caiapó com população de 12 plantas.m ${ }^{-1}$ e espaçamento de 0,50 m; Bulgarelli (2008), descreveu a não influência significativa das densidades de plantas na produtividade de vagens, demostrando a maior produtividade com 22 plantas.m $\mathrm{m}^{-1}$ (4.023 kg.ha $\left.{ }^{-1}\right)$ e a menor com 12 plantas. $\mathrm{m}^{-1}$ (3.481 kg.ha $\left.{ }^{-1}\right)$ com o mesmo genótipo; e Perozini et al. (2014), observaram produtividade em vagens média de aproximadamente 2.400 kg.ha ${ }^{-1}$, sendo-a inferior as menores médias obtidas nos tratamentos de 10 e 15 sementes.m ${ }^{-1}$ (3.324 e $4.196 \mathrm{~kg} \cdot \mathrm{ha}^{-1}$, respectivamente).

\section{EXPERIMENTO 2}

Os resultados da análise de variância e os respectivos valores de quadrados médios (tratamento e bloco), médias e coeficiente de variação (C.V.\%) estão apresentados na Tabela 3. Foi observado a diferença significativa a $5 \%$ de probabilidade, pelo teste $\mathrm{F}$, em função da densidade de sementes.m ${ }^{-1}$ com o genótipo IAC Tatu-ST no ano agrícola 2017/18.

Tabela 3. Quadro da análise de variância de altura de plantas $(\mathrm{cm})$ aos 27 DAE, massa seca por planta (g), número de grãos por planta, número de vagens por planta, massa de 100 grãos $(\mathrm{g})$, produtividade de vagens e grãos $\left(\mathrm{kg} \cdot \mathrm{ha}^{-1}\right)$ em função da densidade de sementes.m ${ }^{-1}$ do genótipo IAC Tatu-ST. Campo Verde, 2017/18.

* significativo $5 \%$ de probabilidade; ns - não significativo.

\begin{tabular}{lcccc}
\hline \multirow{2}{*}{\multicolumn{1}{c}{ Variáveis }} & \multicolumn{2}{c}{ Quadrados Médios } & \multirow{2}{*}{ Média } & \multirow{2}{*}{ C.V.\% } \\
\cline { 2 - 3 } & Tratamento & Bloco & & \\
\hline Altura de plantas aos 27 DAE (cm) & $40,69^{*}$ & $3,45^{\mathrm{ns}}$ & 21,40 & 13,51 \\
Massa seca por planta (g) & $45,45^{\mathrm{ns}}$ & $44,29^{\mathrm{ns}}$ & 24,08 & 31,81 \\
Número de grãos por planta & $137,12^{\mathrm{ns}}$ & $129,65^{\mathrm{ns}}$ & 40,00 & 26,88 \\
Número de vagens por planta & $22,12^{\mathrm{ns}}$ & $27,42^{\mathrm{ns}}$ & 18,40 & 23,91 \\
Massa de 100 grãos (g) & $3,55^{\mathrm{ns}}$ & $0,05^{\mathrm{ns}}$ & 39,18 & 2,88 \\
Produtividade de vagens $\left({\left.\mathrm{kg} . h \mathrm{ha}^{-1}\right)}^{387.509,69^{\mathrm{ns}}}\right.$ & $190.401,98^{\mathrm{ns}}$ & 2.718 & 15,65 \\
Produtividade de grãos $\left(\mathrm{kg} \cdot \mathrm{ha}^{-1}\right)$ & $335.265,39^{\mathrm{ns}}$ & $163.624,01^{\mathrm{ns}}$ & 2.500 & 15,76 \\
\hline
\end{tabular}

Fonte: Elaborado pelos Autores, 2018. 
A Tabela 3 apresenta a altura de plantas $(\mathrm{cm})$ aos 27 DAE, em função da densidade de sementes. $\mathrm{m}^{-1}$ no genótipo IAC Tatu-ST, houve diferença significativa. Verifica-se que não houve diferença significtiva para massa seca por planta $(\mathrm{g})$, número de grãos por planta, número de vagens por planta, massa de 100 grãos (g), produtividades de vagens e grãos $\left(\mathrm{kg}_{\mathrm{h}} \mathrm{ha}^{-1}\right)$.

A altura de plantas (cm) aos 27 DAE, sofreu influência das densidades, com ajuste linear crescente (Figura 3). O tratamento de 30 sementes. $^{-1}(26,10 \mathrm{~cm})$ apresentou a maior altura de plantas e o tratamento de 10 sementes. $\mathrm{m}^{-1}(17,33 \mathrm{~cm})$ a menor. Provavelmente, ao passo que adensa as plantas, aumentando o número de sementes. $\mathrm{m}^{-1}$, ocasiona na competição entre elas por radiação solar, ao passo que resultará no estiolamento, ou seja, conforme o maior número de plantas estabelecidas no mesmo volume de solo elas tendem a crescer mais em busca de radiação para obter taxa fotossíntentica adequadada para se desenvolver.

Figura 3. Alturas de plantas (cm) aos $27 \operatorname{DAE}(\mathrm{A})$, em função da densidade de sementes. $\mathrm{m}^{-1}$ do genótipo IAC Tatu-ST. Campo Verde, 2017/18.

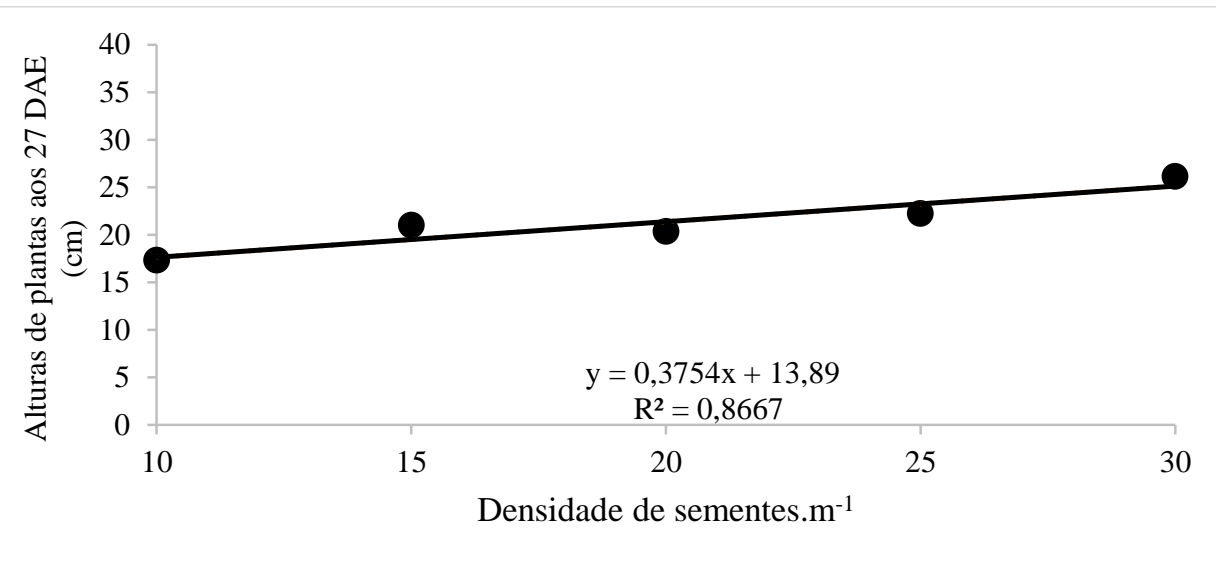

Fonte: Elaborado pelos Autores, 2018.

Estes resultados (Figura 3), estão de acordo com Bellettini e Endo (2001), ao descreverem que conforme o aumento das densidades, observa-se as maiores médias de alturas, para o genótipo Tatu vermelho disposto em diferentes densidades (10, 15, 20 e 25 sementes.m $\left.{ }^{-1}\right)$. Discordando de Almeida Júnior et al. (2013), que aos 30 DAE, para o genótipo IAC Tatu-ST com estande de 15 plantas. $\mathrm{m}^{-1}$, obtiveram altura média de planta $36 \%(32,03 \mathrm{~cm})$ superior a observada no tratamento de 20 sementes do presente estudo $(20,33 \mathrm{~cm})$, que resulta no estande de plantas mais próximo do comparado.

A massa seca por planta (g), em função da densidade de sementes.m ${ }^{-1}$ utilizados no genótipo IAC Tatu-ST não apresentou diferença significativa, com massa média de 24,08 g (Tabela 3). Discordando de Silveira (2010), que estudando os genótipos Vagem Lisa e BRS Havana com diferentes densidades (13 plantas. $\mathrm{m}^{2}, 5$ plantas. $\mathrm{m}^{-1}, 10$ plantas. $\mathrm{m}^{-1}$ e 15 plantas. $\left.\mathrm{m}^{-1}\right)$ e épocas (julho/2008 e abril/2009) encontrou diferença significativa. 
O número de grãos e vagens por planta, em função da densidade de sementes.m-1 utilizados no genótipo IAC Tatu-ST não diferiram significativamente, apresentando médias de 40,00 grãos e 18,40 vagens por planta (Tabela 3). Em relação ao número de grãos por planta, discorda-se de Bellettini e Endo (2001) que obtiveram diferença significativa de forma linear decrescente, em relação a densidade de sementes. Quanto o número de vagens por planta, concorda-se com Bulgarelli (2008), que também não obteve diferença significativa do número de vagens por plantas com o genótipo IAC Tatu-ST; discordando de Fachin et al. (2014), que utilizando o genótipo IAPAR 25 Tição obtiveram médias 33 e 28\% superiores (27,30 e 25,60 vagens por planta) a média do presente trabalho (Tabela 3 ).

A massa de 100 grãos (g), em função da densidade de sementes. $\mathrm{m}^{-1}$ utilizados no genótipo IAC Tatu-ST não diferiu estatisticamente, apresentando massa média de 39,18 g (Tabela 3). Estes resultados são semelhantes ao descrito por Godoy et al. (2003), pois descreveram a massa de 100 grãos para o genótipo IAC Tatu-ST de 41,80 g; e Nakagawa et al. (1994), que também não encontraram diferença estatística com o genótipo Tatu-53 (Vermelho) com espaçamento de 0,60 m e submetido a 7, 10, 13, 16, 19, 22, 25 e 28 sementes.m $^{-1}$. Por outro lado, Câmara (2016), descreve que a massa de 100 grãos para o genótipo IAC Tatu-ST deve ser entre 42,00 e 44,00 g.

Em relação as produtividades de vagens e grãos $\left(\mathrm{kg} \cdot \mathrm{ha}^{-1}\right)$, em função da densidade de sementes. $\mathrm{m}^{-1}$ utilizados no genótipo IAC Tatu-ST não diferiram significativamente. A produtividade de vagens apresentou média de $2.717 \mathrm{~kg}$ ha $^{-1}$ (Tabela 3) e mesmo sem diferença significativa, o tratamento de 20 sementes. $\mathrm{m}^{-1}$ foi superior $\left(3.067 \mathrm{~kg} . \mathrm{ha}^{-1}\right)$, quando comparado a menor média, o tratamento de 10 sementes. $\mathrm{m}^{-1}\left(2.368 \mathrm{~kg} \cdot \mathrm{ha}^{-1}\right)$, apresenta-se $23 \%$ mais produtivo. Estes resultados estão de acordo com Perozini (2003), que observou produtividade média de vagens de $2.748 \mathrm{~kg} \cdot \mathrm{ha}^{-1}$ com o genótipo IAC Tatu-ST; Belletini e Endo (2001) também não encontraram efeito significativo; e Almeida Júnior et al. (2013), observaram produtividade média de vagens de $2.744 \mathrm{~kg} \cdot \mathrm{ha}^{-1}$ com o genótipo IAC Tatu-ST. Discordando de Nakagawa et al. (2000), que observaram diferença significativa nas três safras (1987/88, 1988/89 e 1989/90) com o genótipo Tatu-53 (Vermelho), em ambos estudos o tratamento de 26 plantas. $\mathrm{m}^{-1}$ foi o mais produtivo, apresentando médias superiores nas três safras $\left(4.105,3.699\right.$ e 3.699 kg.ha ${ }^{-1}$, respectivamente).

A produtividade de grãos apresentou média de $2.499 \mathrm{~kg} \cdot \mathrm{ha}^{-1}$ (Tabela 3), não diferindo de forma significativa. $\mathrm{O}$ tratamento de 20 sementes. $^{-1}$ foi superior aos demais $\left(2.824 \mathrm{~kg}\right.$.ha $\left.{ }^{-1}\right)$, pois quando comparado a menor média, o tratamento de 10 sementes. $\mathrm{m}^{-1}\left(2.172 \mathrm{~kg} \cdot \mathrm{ha}^{-1}\right)$, apresenta-se $23 \%$ mais produtivo. Isso discorda com Peixoto et al. (2008), que obtiveram diferença significativa na produtividade de grãos para a cultivar ereta Vagem Lisa submetido a três densidades $\left(5,10\right.$ e 15 plantas. $\left.\mathrm{m}^{-1}\right)$ e duas épocas de plantio no espaçamento de 0,50 m; Fachin et 
al. (2014), estudando diferentes cultivares semeadas em espaçamento de 0,70 m e população de 15 plantas. $\mathrm{m}^{-1}$, obtiveram com o genótipo rasteiro IAPAR 25 Tição produtividade média de 2.560 kg.ha ${ }^{-1}$ e 2.573 kg.ha ${ }^{-1}$, em Marechal Cândido Rondon-PR e Tupãssi-PR, respectivamente.

\section{EXPERIMENTO 3}

Os resultados da análise de variância e os respectivos valores de quadrados médios (tratamento e bloco), médias e coeficiente de variação (C.V.\%) estão apresentados na Tabela 4. Foi observado a diferença significativa a $5 \%$ de probabilidade, pelo teste $\mathrm{F}$, em função da densidade de sementes.m ${ }^{-1}$ do genótipo IAC Caiapó no ano agrícola 2018/19.

Tabela 4. Quadro da análise de variância de altura de plantas $(\mathrm{cm})$ aos $32 \mathrm{DAE}$, massa seca por planta (g), número de grãos por planta, número de vagens por planta, massa de 100 grãos (g), produtividade de vagens e grãos $\left(\mathrm{kg} \cdot \mathrm{ha}^{-1}\right)$ em função da densidade de sementes. $\mathrm{m}^{-1}$ do genótipo IAC Caiapó. Campo Verde, 2018/19.

\begin{tabular}{lcccc}
\hline \multicolumn{1}{c}{ Variáveis } & \multicolumn{2}{c}{ Quadrados Médios } & \multirow{2}{*}{ Média } & \multirow{2}{*}{ C.V.\% } \\
& Tratamento & Bloco & & \\
\hline Altura de plantas aos 32 DAE (cm) & $29,55^{*}$ & $7,04^{\mathrm{ns}}$ & 26,18 & 9,41 \\
Massa seca por planta (g) & $83,14^{\mathrm{ns}}$ & $32,96^{\mathrm{ns}}$ & 17,20 & 34,96 \\
Número de grãos por planta & $237,98^{*}$ & $24,43^{\mathrm{ns}}$ & 25,51 & 26,61 \\
Número de vagens por plana & $77,81^{*}$ & $19,82^{\mathrm{ns}}$ & 17,40 & 23,32 \\
Massa de 100 grãos (g) & $0,95^{\mathrm{ns}}$ & $13,43^{\mathrm{ns}}$ & 63,33 & 3,50 \\
Produtividade de vagens $\left(\mathrm{kg.ha}^{-1}\right)$ & $242.941,31^{\mathrm{ns}}$ & $566.098,83^{\mathrm{ns}}$ & 5.340 & 16,13 \\
Produtividade de grãos $\left(\mathrm{kg.ha}^{-1}\right)$ & $187.938,93^{\mathrm{ns}}$ & $261.537,40^{\mathrm{ns}}$ & 4.105 & 15,84 \\
\hline
\end{tabular}

* significativo $5 \%$ de probabilidade; ns - não significativo.

Fonte: Elaborado pelos Autores, 2019.

A Tabela 4 apresenta a altura de plantas $(\mathrm{cm})$ aos 32 DAE, número de grãos por planta e número de vagens por planta em função da densidade de sementes. $\mathrm{m}^{-1}$ no genótipo IAC Caiapó, houve diferença significativa. Verifica-se que não houve diferença significativa para massa seca por planta (g), massa de 100 grãos (g), produtividades de vagens e grãos $\left(\mathrm{kg} \cdot \mathrm{ha}^{-1}\right)$

Sobre a altura de plantas $(\mathrm{cm})$ aos 32 DAE, houve influência das densidades, com ajuste quadrático (Figura 4.A). A maior altura de plantas $(28,30 \mathrm{~cm})$ utilizando 25,4 sementes. $\mathrm{m}^{-1}$. Estes resultados concordam com Perozini (2003), que encontrou altura média aos 30 DAE com o genótipo IAC Caiapó de $27,32 \mathrm{~cm}$, cultivando os experimentos com espaçamento de 0,60 m e população de 15 plantas. ${ }^{-1}$, que resulta em altura semelhante ao referido tratamento de 20 sementes. $\mathrm{m}^{-1}(27,75 \mathrm{~cm})$ aos 32 DAE. 
Figura 4. Altura de plantas $(\mathrm{cm})$ aos $32 \operatorname{DAE}(\mathrm{A})$, número de grãos por planta $(\mathrm{B})$ e número de vagens por planta $(C)$, em função da densidade de sementes. $m^{-1}$ do genótipo IAC Caiapó. Campo Verde, 2018/19.

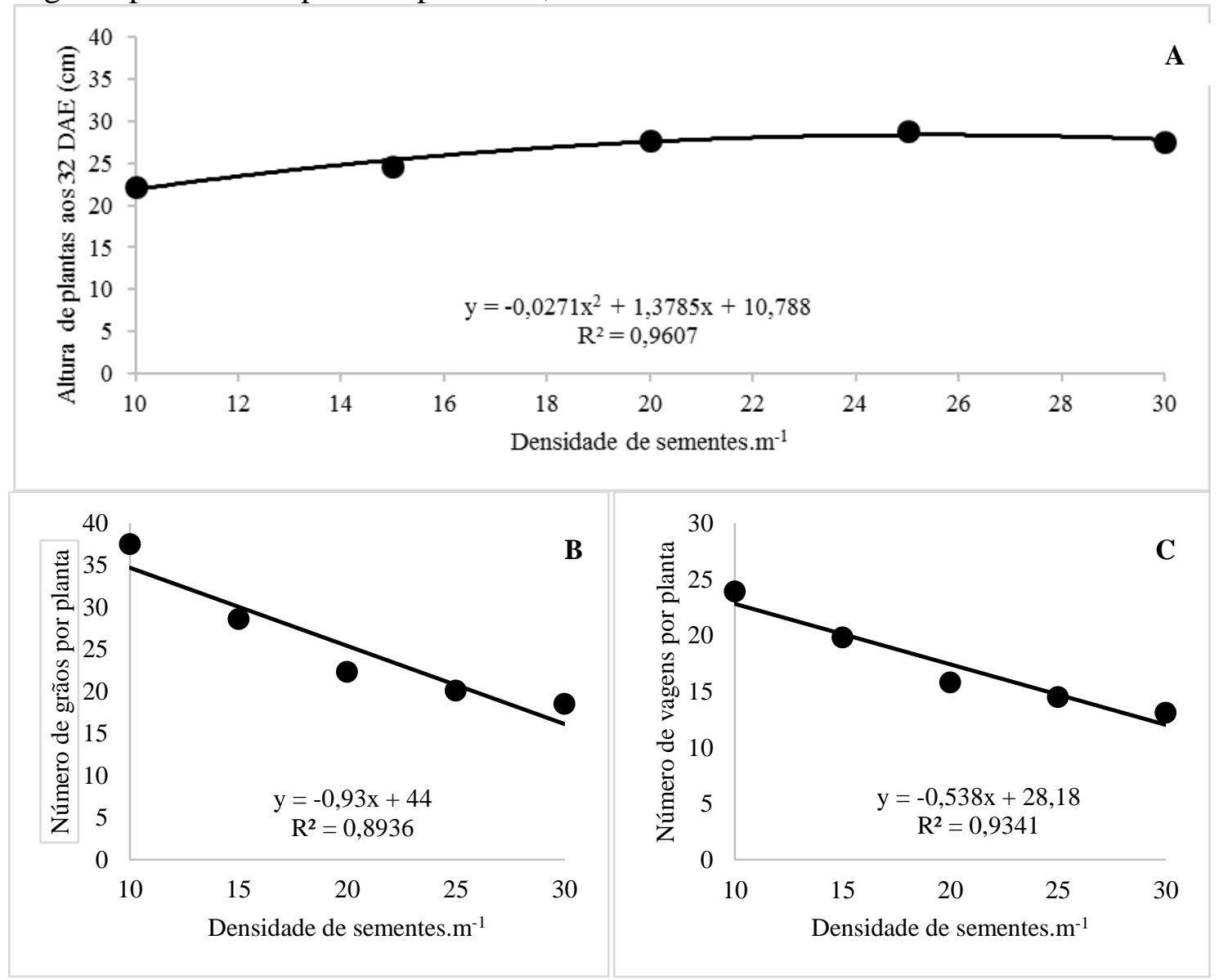

Fonte: Elaborado pelos Autores, 2019.

Em relação a massa seca por planta $(\mathrm{g})$, em função da densidade de sementes.m ${ }^{-1}$ utilizados no genótipo IAC Caiapó não houve diferença significativa, com massa média de 17,20 g (Tabela 4). Discordando de Romanini Junior (2007), que estudando um fatorial de espaçamentos (linha simples de $0,90 \mathrm{~m}$ e linha dupla de $0,17 \mathrm{~m}$ x 0,73 m) e densidades $(6,9,12$, 15 e 18 plantas.m ${ }^{-1}$ ) com o cultivar Runner IAC 886, encontrou diferença significativa no fator densidade apenas, na variável massa seca de plantas $\left(\mathrm{kg} \cdot \mathrm{ha}^{-1}\right)$ em dois experimentos.

O número de grãos por planta, apresentou diferença significativa nas diferentes densidades de sementes. $\mathrm{m}^{-1}$, com ajuste linear decrescente (Figura 4.B). Verifica-se que o tratamento de 10 sementes. $\mathrm{m}^{-1}$ (37,50 grãos por planta) apresentou o maior número de grãos por planta e o tratamento de 30 sementes. $\mathrm{m}^{-1}$ (18,50 grãos por planta) o menor. Concordando com Bellettini e Endo (2001), que também obtiveram efeito linear decrescente com o genótipo Tatu vermelho submetido a diferentes densidades de sementes $\left(10,15,20\right.$ e 25 sementes.m $\left.^{-1}\right)$.

O número de vagens por planta, sofreu influência estatística das densidades de sementes. $\mathrm{m}^{-1}$, com ajuste linear decrescente (Figura 4.C). No tratamento de 10 sementes. $\mathrm{m}^{-1}$ (23,90 vagens por planta) apresentou maior número de vagens por planta e o tratamento de 30 
sementes.m ${ }^{-1}$ (13,10 vagens por planta) o menor. Com base nisso, concorda-se com Néris (2005), que obteve média de 15,10 vagens por planta com estudo no genótipo IAC Caiapó submetido a diferentes espaçamentos $(0,70 \mathrm{~m}$ e $0,90 \mathrm{~m})$ e modos de aplicação de inseticidas (tratamento de sementes e pulverização foliar; pulverização foliar; e sem controle), em Selvíria-MS. Discordando de Santos et al. (1997), que com base na média de 5 genótipos rasteiro, descrevem uma média de 34 vagens por planta, sendo $42 \%$ superior ao observado no tratamento de melhor desempenho do presente estudo (10 sementes. $\left.\mathrm{m}^{-1}\right)$.

A massa de 100 grãos (g), em função da densidade de sementes. $\mathrm{m}^{-1}$ utilizados no genótipo IAC Caiapó não diferiu significativamente, apresentando massa média (Tabela 4) de 63,33 g. Estes resultados discordam de Perozini et al. (2014), que obtiveram massa média de 100 grãos inferior 21\% (50,10 g) para o genótipo IAC Caiapó; e Bolonhezi et al. (2001), que estudando o comportamento do genótipo IAC Caiapó sob diferentes sistemas de cultivo na seca (convencional, cultivo mínimo e plantio direto sobre a palhada de cana-de-açúcar), obtiveram massa de 100 grãos de 70,80 g, superior à média (Tabela 4) em 12\%, em Ribeirão Preto-SP.

Sobre as produtividades de vagens e grãos $\left(\mathrm{kg} \cdot \mathrm{ha}^{-1}\right)$, em função da densidade de sementes.m ${ }^{-1}$ utilizados no genótipo IAC Caiapó não houve diferença significativa. A produtividade de vagens apresentou média de $5.340 \mathrm{~kg}^{-} \mathrm{ha}^{-1}$ (Tabela 4), com isso, mesmo sem

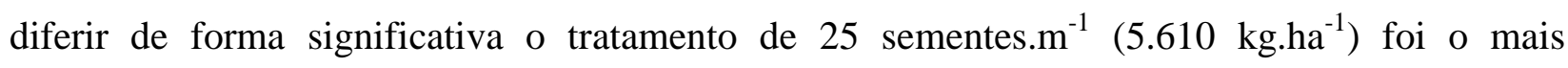
produtivo e o de 10 sementes.m $\mathrm{m}^{-1}\left(5.068 \mathrm{~kg} \cdot \mathrm{ha}^{-1}\right)$ o menos. Concordando com Bulgarelli (2008), que também não obteve diferença significativa com os genótipos IAC Caiapó e Runner IAC 886, submetidos as 4 densidades de plantas (6, 12, 18 e 22 plantas.m $\left.{ }^{-1}\right)$; Ferraz et al. (2017), que cultivando o genótipo Runner IAC 886 disposto em linhas simples com estandes finais de 6,4; 10,8; e 13,6 pl.m ${ }^{-1}$, resultou em produtividades de 5.359; 6.020; e 5.884 kg.ha ${ }^{-1}$, respectivamente; e Godoy et al. (2003), estudando o desempenho de genótipos observaram produtividades de 5.525 e $5.110 \mathrm{~kg} \cdot \mathrm{ha}^{-1}$, respectivamente, cultivando os genótipos Runner IAC 886 e IAC Caiapó.

A produtividade de grãos apresentou média de $4.105 \mathrm{~kg} \cdot$ ha $^{-1}$ (Tabela 4), não diferenciando de forma significativa para os tratamentos. Entretanto, houve diferença de $485 \mathrm{~kg} \cdot \mathrm{ha}^{-1}$ entre os tratamentos com 10 e 25 sementes.m ${ }^{-1}$. O Instituto Agronômico de Campinas (1998), descreve que o genótipo IAC Caiapó tem produtividade média de $4.550 \mathrm{~kg} \cdot \mathrm{ha}^{-1}$ de frutos. Mingotte et al. (2019), descreve a produtividade média de grãos (4.000 kg.ha $\left.{ }^{-1}\right)$ para o genótipo IAC Caiapó semelhante a obtida no presente estudo. Discordando de Néris (2005), que obteve produtividades inferiores utilizando os genótipos IAC Caiapó (2.366 kg.ha $\left.{ }^{-1}\right)$ e Runner IAC 886 (1.966 kg.ha $\left.{ }^{-1}\right)$, em diferentes espaçamentos e modos de aplicação de inseticidas. Godoy et al. (2003), estudando os genótipos de amendoim (Runner IAC 886, IAC Caiapó e Runner), com produção de grãos de 
peneira igual ou maior que 22, obtiveram produtividades médias de $4.091,3.711$ e $3.083 \mathrm{~kg} . \mathrm{ha}^{-1}$ em três anos de experimentos, respectivamente.

\section{EXPERIMENTO 4}

Os resultados da análise de variância e os respectivos valores de quadrados médios (tratamento e bloco), médias e coeficiente de variação (C.V.\%) estão apresentados na Tabela 5. Foi observado a diferença significativa a $5 \%$ de probabilidade, pelo teste $\mathrm{F}$, em função da densidade de sementes.m ${ }^{-1}$ com o genótipo IAC Tatu-ST no ano agrícola 2018/19.

Tabela 5. Quadro da análise de variância de altura de plantas $(\mathrm{cm})$ aos 32 DAE, massa seca por planta (g), número de grãos por planta, número de vagens por planta, massa de 100 grãos (g), produtividade de vagens e grãos $\left(\mathrm{kg} . \mathrm{ha}^{-1}\right)$ em função da densidade de sementes. $\mathrm{m}^{-1}$ do genótipo IAC Tatu-ST. Campo Verde, 2018/19.

\begin{tabular}{lcccc}
\hline \multicolumn{1}{c}{ Variáveis } & \multicolumn{2}{c}{ Quadrados Médios } & \multirow{2}{*}{ Média } & \multirow{2}{*}{ C.V.\% } \\
& Tratamento & Bloco & & \\
\hline Altura de plantas aos 32 DAE (cm) & $49,97^{*}$ & $2,03^{\text {ns }}$ & 40,07 & 6,34 \\
Massa seca por planta (g) & $55,77^{\text {ns }}$ & $33,92^{\text {ns }}$ & 27,33 & 22,47 \\
Número de grãos por planta & $150,40^{*}$ & $25,41^{*}$ & 44,51 & 5,99 \\
Número de vagens por planta & $19,10^{\text {ns }}$ & $13,74^{\text {ns }}$ & 19,80 & 14,22 \\
Massa de 100 grãos (g) & $4,70^{\text {ns }}$ & $42,92^{\text {ns }}$ & 44,63 & 6,84 \\
Produtividade de vagens $\left({\mathrm{kg} . h a^{-1}}^{-1}\right)$ & $54.946,05^{\text {ns }}$ & $27.316,39^{\text {ns }}$ & 3.096 & 7,84 \\
Produtividade de grãos $\left(k g . \mathrm{ha}^{-1}\right)$ & $46.594,50^{\text {ns }}$ & $19.371,85^{\text {ns }}$ & 2.790 & 7,75 \\
\hline
\end{tabular}

* significativo $5 \%$ de probabilidade; ns - não significativo.

Fonte: Elaborado pelos Autores, 2019.

A Tabela 5 apresenta a altura das plantas $(\mathrm{cm})$ aos 32 DAE e número de grãos por planta, em função da densidade de sementes no genótipo IAC Tatu-ST, houve diferença significativa. Verifica-se que não houve diferença significativa para massa seca por planta (g), número de vagens por planta, massa de 100 grãos $(\mathrm{g})$, produtividade de vagens e grãos $\left(\mathrm{kg}_{\mathrm{h}} \mathrm{ha}^{-1}\right)$.

A altura de plantas $(\mathrm{cm})$ aos 32 DAE, sofreu influência das densidades, com ajuste quadrático (Figura 5.A), a densidade de 27,4 sementes. $\mathrm{m}^{-1}$ resulta em altura máxima de plantas. Nesse sentido, discorda-se de Almeida Júnior et al. (2013), que obtiveram média de altura aos 30 DAE $(32,03 \mathrm{~cm}) 20 \%$ menor que a média geral de 40,07 cm (Tabela 5) com o mesmo genótipo. 
Figura 5. Altura de plantas $(\mathrm{cm})$ aos 32 DAE (A) e número de grãos por planta (B), em função da densidade de sementes. $\mathrm{m}^{-1}$ do genótipo IAC Tatu-ST. Campo Verde, 2018/19.
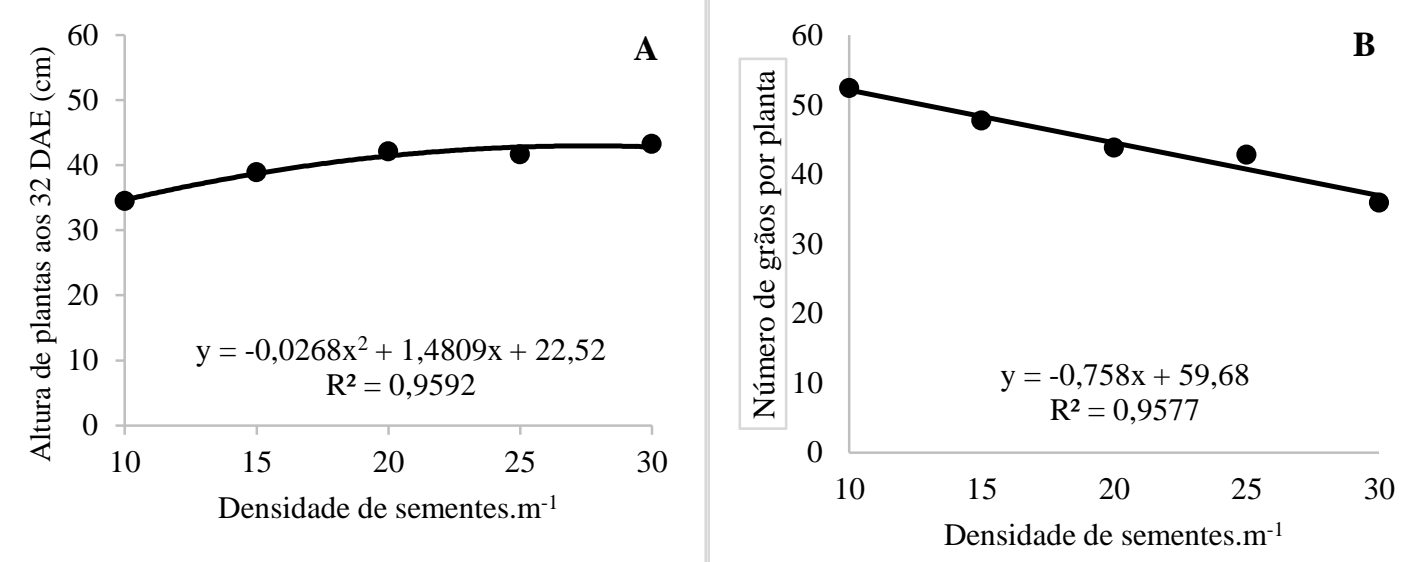

Fonte: Elaborado pelos Autores, 2019.

A massa seca por planta (g), em função da densidade de sementes.m ${ }^{-1}$ utilizados no genótipo IAC Tatu-ST não apresentou diferença significativa, com massa média de 27,33 g (Tabela 5). Concordando com Silva et al. (2006), que estudando os descritores produtivos de duas linhagens anfidiploides (Baio Forrageiro e Runner Forrageiro), observaram massas secas médias semelhantes ao presente estudo (30,00 e 31,00 g, respectivamente).

O número de grãos por planta, apresentou diferença estatística nas diferentes densidades de sementes. $\mathrm{m}^{-1}$, com ajuste linear decrescente (Figura 5.B) e média geral de 44,51 grãos por planta. Observa-se que o tratamento de 10 sementes. $\mathrm{m}^{-1}$ (52,40 grãos) obteve maior massa e o de 30 sementes. $\mathrm{m}^{-1}$ a menor (35,90 grãos). Concordando com Oliveira Júnior et al. (2004), que observaram diferença significativa e obtiveram média de 44,10 grãos por planta, com estudo do desempenho das cultivares Tatu e PI-165317 submetida a condição hídrica adequada. Discordando de Conagin e Conagin (1960), que obtiveram 39 frutos maduros por planta com a cultivar Tatu.

O número de vagens por planta, em função da densidade de sementes. $\mathrm{m}^{-1}$ utilizados no genótipo IAC Tatu-ST não diferiram significativamente, apresentando média de 19,80 vagens por planta (Tabela 5). Verifica-se que o número de vagens por planta do genótipo IAC Tatu-ST apresentaram resultados correlatos nos Experimentos 2 e 4 (Tabela 3 e 5). Concordando com Santos et al. (1997), que com base na média de 5 genótipos decumbentes e 5 genótipos rasteiros obteve número médio de 17,00 vagens por planta em ambos genótipos, semelhante à média geral. Discordando de Kanesiro et al. (1989), que estudando a cultivar Tatu-53 com amonta e sem amonta na colheita, observaram médias de 7,46 e 7,29 vagens por planta, respectivamente, sendoas 62 e $63 \%$ menores à média geral.

A massa de 100 grãos (g), em função da densidade de sementes. $\mathrm{m}^{-1}$ utilizados no genótipo IAC Caiapó não diferiu significativamente, apresentando massa média de 44,63 g (Tabela 5). 
Estes resultados concordam com Godoy et al. (2003), que em experimentos comparando as cultivares (IAC-5, IAC-22, IAC-8112 e IAC Tatu-ST), obtiveram massa média de 100 grãos de 41,80 g com o genótipo IAC Tatu-ST, sendo os dados médios de 5 experimentos realizados em Ribeirão Preto e Pindorama-SP; Pompeu (1985), obteve massa média de 100 grãos de 44,40 g, com o genótipo Tatu vermelho em experimento de desempenho de cultivares (IAC-Oirã, IACPoitara, IAC-Tupã e Tatu vermelho) nos cultivos das águas e da seca.

Em relação as produtividades de vagens e grãos $\left(\mathrm{kg} \cdot \mathrm{ha}^{-1}\right)$, em função da densidade de sementes.m ${ }^{-1}$ utilizados no genótipo IAC Tatu-ST não diferiram significativamente. A produtividade de vagens apresentou média de 3.096 kg.ha-1 (Tabela 5) e mesmo sem diferença significativa, o tratamento de 20 sementes. $\mathrm{m}^{-1}$ apresentou maior produtividade $\left(3.244 \mathrm{~kg} \cdot \mathrm{ha}^{-1}\right)$. Estes resultados concordam com Godoy et al. (2003), obtiveram em experimentos realizados em Tupã (médias de três anos agrícolas) produtividade de vagens de $3.271 \mathrm{~kg} \cdot \mathrm{ha}^{-1}$, semelhante a maior produtividade do presente estudo (20 sementes.m ${ }^{-1}$ ); Nakagawa et al. (1983), estudando a cultivar Tatu na época das águas, submetida a diferentes densidades de sementes $(10,15,20$ e 25 sementes. $\mathrm{m}^{-1}$ ), observaram com 20 sementes. $\mathrm{m}^{-1}$ a produtividade de vagens de $3.008 \mathrm{~kg} . \mathrm{ha}^{-1} \mathrm{em}$ São Manuel-SP no ano agrícola 1978/79. Por outro lado, discorda-se de Bulgarelli (2008), que observou diferença significativa na produtividade de vagens do genótipo IAC Tatu-ST submetido a diferentes densidades de plantas, e obteve a maior produtividade com a densidade de 22 plantas. $\mathrm{m}^{-1}\left(1.371 \mathrm{~kg} \cdot \mathrm{ha}^{-1}\right)$.

A produtividade de grãos apresentou média de $2.790 \mathrm{~kg}^{\circ} \mathrm{ha}^{-1}$ (Tabela 5), não diferindo de forma significativa, o tratamento de 20 sementes. $\mathrm{m}^{-1}$ foi superior aos demais $\left(2.927 \mathrm{~kg} . \mathrm{ha}^{-1}\right)$, pois quando comparado a menor média, o tratamento de 10 sementes. $^{-1}\left(2.633 \mathrm{~kg} . \mathrm{ha}^{-1}\right)$, apresenta-se $12 \%$ mais produtivo. Constata-se que as produtividades de vagens e grãos do genótipo IAC TatuST apresentaram resultados correlatos nos Experimentos 2 e 4 (Tabela 3 e 5), sendo o Experimento 4 com médias superiores. Os autores Mingotte et al. (2019) e Câmara (2016), descreveram a produtividade média de grãos para o genótipo IAC Tatu-ST de 3.100 kg.ha-1 ${ }^{-1}$. Kanesiro et al. (1989), obtiveram produtividades médias de grãos de 1.051 e 1.041 kg.ha ${ }^{-1}$, com e sem amontoa na colheita da cultivar Tatu-53, respectivamente, sendo-as 62\% menores do que a média geral do presente estudo (Tabela 5).

\section{CONCLUSÃO}

Nas condições de campo em que foi desenvolvido esta pesquisa, pode-se concluir que:

- A produtividade de vagens e grãos no genótipo IAC Caiapó, obteve-se o maior valor médio em 24 sementes. $\mathrm{m}^{-1}$. 
- Independente da densidade de sementes a produtividade de vagens e grãos é a mesma estatisticamente para o genótipo IAC Tatu-ST.

\section{REFERENCIAS}

ALMEIDA JÚNIOR, J. J.; PEROZINI, A. C.; THOMAS, P. C. Resistência de genótipos de amendoinzeiro Arachis hypogaea, de hábito de crescimento ereto, ao tripes do prateamento $E$. flavens e potencial produtivo. Nucleus, v. 10., n. 2, p. 151-164, 2013. ISSN 1982-2278. Disponível em: 〈http://www.nucleus.feituverava.com.br/index.php/nucleus/article/view/930〉. Acesso em: 04 may 2020. doi:http://dx.doi.org/10.3738/1982.2278.930.

BARBIERI, J. D.; DALLACOR, R.; FARIA JÚNIOR, C. A.; FREITAS, P. S. L.; FENNER, W. Ensaio de épocas e densidade de plantas de duas cultivares de amendoim. Nucleus, v. 13, n. 1, p. 111-122, 2016. ISSN 1982-2278. Disponível em:

<http://www.nucleus.feituverava.com.br/index.php/nucleus/article/view/1599>. Acesso em: 04 may 2020. doi:http://dx.doi.org/10.3738/1982.2278.1599.

BELLETTINI, N. M. T.; ENDO, R. M. Comportamento do amendoim “das águas”, Arachis hypogaea L., sob diferentes espaçamentos e densidades de semeadura. Acta Scientiarum, Maringá, v. 23, n. 5, p. 1249-1256, 2001.

BERTIOLI, D. J.; SEIJO, G.; FREITAS, F. O.; VALLS, J. F. M.; BERTIOLI, S. C. M. L.; MORETZSOHN, M. C. An overview of peanut and its wild relatives. Plant Genetic Resources: characterization and utilization, n. 9, p. 134-149, 2011.

BOIÇA JUNIOR, A. L.; CHAGAS FILHO, N. R.; GODOY, I. J.; LOURENÇÃO, A. L. SOUZA, J. R. Avaliação de resistência de cultivares de amendoim de hábito de crescimento rasteiro a Enneothrips flavens Moulton (Thysanoptera: Thripidae). Arquivos do Instituto Biológico, São Paulo, v. 79, n. 1, p. 33-38, 2012.

BOLONHEZI, D.; PEREIRA, J. C. V. N. A.; DE SORDI, G.; GODOY, I. J.; CANTARELLA, H. Comportamento de duas cultivares de amendoim nos sistemas convencional, cultivo mínimo e plantio direto sobre a palhada de cana-de-açúcar. In: Congresso Brasileiro de Ciência do Solo, 28., 2001, Londrina. Resumos... Londrina: Embrapa-CNPSO, 2001. p. 261.

BULGARELLI, E. M. B. Caracterização de variedades de amendoim cultivadas em diferentes populações. 2008. 61 f. Dissertação (Mestrado em Agronomia) - Faculdade de Ciências Agrárias e Veterinárias Campus de Jaboticabal, Universidade Estadual Paulista "Julio de Mesquita Filho", Jaboticabal-SP, 2008.

CÂMARA, G. M. S. Estudo da planta do amendoim. Piracicaba, 2016. Disponível em: $<$ http://docplayer.com.br/46155475-Estudo-da-planta-de-amendoim.html $>$. Acesso em: 12 fev. 2019.

CONAB: Acompanhamento da Safra Brasileira de grãos, v. 6 - Safra 2018/19 - Décimo segundo levantamento, Brasília, p. 1-126, set. 2019.

CONAGIN, C. H. T. M.; CONAGIN, A. Eficiência reprodutiva no amendoim cultivado (Arachis hypogaea L.) Bragantia, Campinas, v. 19, p. 1081-1104, 1960. 
COX, F. R; REID, P. H. Interaction of plant population factors and level of production an yield and grade of peanuts. Agronomy Journal, v. 57, p. 455-456, 1965.

Classificação climática de Köppen-Geiger. Disponível em:

$\langle$ https://portais.ufg.br/up/68/o/Classifica____Clim_tica_Koppen.pdf $>$. Acesso em: 18 maio 2018.

FACHIN, G. M; JUNIOR, J. B. D.; GLIER, C. A. da S.; MROZINSKI, C. R.; DA COSTA, A. C. T.; GUIMARÃES, V. F. Características agronômicas de seis cultivares de amendoim cultivadas em sistema convencional e de semeadura direta. Campina Grande: R. Bras. Eng. Agríc.

Ambiental, v. 18, n. 2, p. 165-172, 2014.

FERRAZ, M.; MICHELOTTO, M. D.; SOUZA, T. M.; PIVARO, R. S.; MARTINS, A. L. M.; GODOY, I. J. Efeito da densidade de plantas e do padrão de linhas de plantio na incidência do Groundnut Ring Spot Virus em amendoim. In: Anais do encontro sobre a cultura do amendoim, 14., 2017, Jaboticabal. Anais eletrônicos... Campinas, GALOÁ, 2018.

FERREIRA, D. F. Sisvar: a Guide for its Bootstrap procedures in multiple comparisons. Ciênc. agrotec. [online]. 2014, v. 38, n. 2, p. 109-112. Disponível em:

<http://dx.doi.org/10.1590/S1413-70542014000200001>. Acesso em: 4 maio 2018.

GODOY, I. J.; MINOTTI, D.; RESENDE, P. L. Produção de amendoim de qualidade. Viçosa: Centro de Produção Técnicas, 2005. 168 p.

GODOY, I. J.; RODRIGUES FILHO, F. S. O.; GERIN, M. A. N.; FEITOSA, C. T. Amendoim. In: FAHL, J. I.; CAMARGO, M. B. P.; PIZZINATTO, M. A.; BETTI, J. A.; MELO, A. M. T.; DEMARIA, I. C.; FURLANI, A. M. C. Instrução agrícola para as principais culturas econômicas. 6. Ed. Campinas: IAC, 1998. p. 303-304.

GODOY, I. J.; MORAES, S. A.; KASAI, F. S.; MARTINS, A. L. M.; PEREIRA, J. C. V. N. A.; MORAES, A. R. A.; TEIXEIRA, J. P. F. Cultivares IAC de amendoim. O Agronômico,

Campinas, v. 55, n. 1, p. 26-29, 2003.

INSTITUTO NACIONAL DE METEOROLOGIA (INMET). Disponível em: <http://www.inmet.gov.br/sonabra/pg_dspDadosCodigo_sim.php?QTkxMg==> Acesso em: 5 jan. 2019.

INSTITUTO AGRONÔMICO DE CAMPINAS. IAC-Caiapó: um amendoim de alta rentabilidade. O Agronômico, v. 47-50, p. 66-67, 1998.

KANESIRO, M. A. B.; CAZETTA, J.O.; FALEIROS, R. R. S.; BELLINGIERI, P. A.; BRUNINI, O. Aspectos qualitativos e quantitativos de grãos de plantas de amendoim (Arachis hypogaea L.) submetidas a diferentes tipos de manejo. Científica, São Paulo, v. 17, n. 2, p. 179$188,1989$.

MOZINGO, R. W.; WRIGHT, F. S. Diamond-shaped seeding of six peanut cultivars. Peanut Science, Raleigh, v. 21, n. 1, p. 5-9, 1994. 
MINGOTTE, F.; MORELLO, O. F.; LEMOS, L. B. Amendoim: origem, classificação e produção. In: SILVA, R. P.; SANTOS, A. F.; CARREGA, W. C. Avanços na produção de amendoim. Jaboticabal: FUNEP, 2019. p. 1-16.

NAKAGAWA, J.; NOJIMOTO, T.; ROSOLEM, C.A.; ALMEIDA, A.M. de; LASCA, D.H.C. Efeitos da densidade de semeadura da produção de vagens de amendoim. Científica, São Paulo, v. 11, n. 1, p.79-86, 1983.

NAKAGAWA, J.; LASCA, D. C.; NEVES, J. P. S.; NEVES, G. S.; SANCHEZ, S. V.; BARBOSA, V.; SILVA, M. N.; ROSSETO, C. A. V. Efeito da densidade de semeadura na produção de amendoim. Pesquisa Agropecuária Brasileira, Brasília, v. 29, n. 10, p. 1547-1555, 1994.

NAKAGAWA, J.; LASCA, D. C.; NEVES, J. P. S.; NEVES, G. S.; SANCHEZ, S. V.; BARBOSA, V.; SILVA, M. N.; ROSSETO, C. A. V. Densidade de plantas e produção de amendoim. Scientia Agrícola, Piracicaba, v. 57, n. 1, p. 67-73, 2000.

NÉRIS, C. N. Cultivares, espaçamentos e modos de aplicação de inseticidas sobre a população de tripes do prateamento Enneothrips flavens Moulton

(Thysanoptera:Thripidae) e seus reflexos na produção do amendoinzeiro. 2005. $73 \mathrm{f}$.

Dissertação (Mestrado em Agronomia) - Faculdade de Engenharia Campus de Ilha Solteira, UNESP. Ilha Solteira-SP. 2005.

OLIVEIRA, T. M. M.; QUEIROGA, R. C. F.; NOGUEIRA, F. P.; MOREIRA, J. N.; DOS SANTOS, M. A. Produção de cultivares decumbentes de amendoim submetidas a distintos espaçamentos. Revista Caatinga, Mossoró, v. 23, n. 4, p. 149-154, 2010.

OLIVEIRA JÚNIOR, J. O. L. TÁVORA, F. J. A. F.; BARBOSA FILHO, M. Fenologia de variedades de amendoim submetidas a ciclos de deficiência hídrica. Científica, Jaboticabal, v. 32, n. 1, p. 25-29, 2004.

PEIXOTO, P. C.; GONÇALVES, J.; DA SILVA P. P., FÁTIMA, M. DE; DARCILÚCIA, O. C. Características agronômicas e produtividade de amendoim em diferentes espaçamentos e épocas de semeadura no Recôncavo Baiano. Bragantia, v. 67, n. 3, p. 673-684, 2008.

PEROZINI, A. C. Resistência ao tripes do prateamento e potencial produtivo de genótipos de amendoim. 2003. 107f. Dissertação (Mestrado em Agronomia) - Faculdade de Engenharia Campus de Ilha Solteira, UNESP. Ilha Solteira-SP, 2003.

PEROZINI, A. C.; SILVA, P. S.; GOUSSAIN, R. C. S. Resistência ao tripes Enneothrips flavens Moulton (Thysanoptera: Thripidae) e o potencial produtivo em genótipos de amendoim de hábito de crescimento rasteiro. Vértices, v. 16, n. 2, p. 79-92, 2014.

POMPEU, A. S. Novos cultivares do IAC: amendoim. O Agronômico, Campinas, v. 37, n. 2, p. 87-88, 1985.

ROMANINI JUNIOR, A. Influência do espaçamento de plantas no crescimento, produtividade e rendimento do amendoim rasteiro, cultivar runner IAC 886. 2007. 60 f. Dissertação (Mestrado em Produção Vegetal) - Faculdade de Ciências Agrárias e Veterinárias, UNESP, Jaboticabal-SP, 2007. 
SANTOS, R. C.; FREIRE R. M. M.; LIMA, L. M. O agronegócio do amendoim no Brasil. 2. ed. Brasília: EMBRAPA, 2013. 585 p.

SANTOS, R. C. MORAES, J. S.; GUIMARÃES, M. B. Caracteres de floração e reprodução em genótipos de amendoim do tipo ereto, ramador e decumbente. Pesquisa Agropecuária Brasileira, Brasília, v. 32, n. 12, p. 1257-1262. 1997.

SHOLAR, J. R.; MOZINGO, R. W.; BEASLEY JUNIOR., J. P. Peanut Cultural Practices. In: PATEE, H. E.; STALKEAR, H. T. (Ed.). Advances in peanut science. Stillwater: American Peanut Research and Education Society, p. 354-382, 1995.

SILVA, C. R. C.; GOMES, L. R.; SANTOS, R. C.; FAVERO, A.; MELO FILHO, P. A. Avaliação produtiva e bromatologica de um anfidiploide sintético de Arachis com potencial para fins forrageiro. In: Jornada de Ensino Pesquisa e Extensão, 6., 2006, Recife. Anais... Recife: Ed. da Universidade Federal Rural de Pernanbuco, 2006.

SILVEIRA, P. S. Época de semeadura e densidade de plantas em cultivares de amendoim no reconcavo sul bahiano. 2008. 112 f. Dissertação (Mestrado em Ciências Agrárias) Universidade Federal do Recôncavo da Bahia, Centro de Ciências Agrárias, Ambientais e Biológicas, Cruz das Almas-BA, 2010. 